\title{
Investigation of Molecular Modeling And Molecular Dynamics Simulation In BRCA-1 And BRCA-2 Genes of Amygdalin Ligand
}

Erkan ÖNER ( $\square$ erkanoner0803@gmail.com )

Mersin Üniversitesi https://orcid.org/0000-0002-6332-6484

Ilter demirhan

Harran University

Arabinda GHOSH

Gauhati University

Meltem GUNGOR

Sanko University

Ali Erdinc YALIN

Mersin University

Serap YALIN

Mersin University

\section{Research Article}

Keywords: Amygdalin, Breast cancer, BRCA-1, BRCA-2, Molecular Modeling, Molecular Dynamics Simulation

Posted Date: September 20th, 2021

DOl: https://doi.org/10.21203/rs.3.rs-767397/v1

License: (c) (i) This work is licensed under a Creative Commons Attribution 4.0 International License. Read Full License 


\section{Abstract}

Breast cancer is the most common type of cancer and the most fatal type among women. BRCA-1 and BRCA-2 are tumor suppressor genes known to cause breast cancer. Drug studies have become very important to target the production of more accurate drugs by reducing the cost with the previous designs of drugs in this field. Amygdalin is used in the treatment of especially cancer, characterized by the loss of red blood cell production. In this study, which was conducted for the first time, it was aimed to examine the use of amygdalin in breast cancer treatment by coupling to the active regions of BRCA- 1 and BRCA-2 genes by molecular docking method. The best attachment scores were selected. Amygdalin was taken from PubChem database in sdf format. According to the molecular insertion results, the free energy of the amygdalin ligand for binding to the BRCA-1 protein was $-4.8 \mathrm{kcal} / \mathrm{mol}$ and the free energy for binding to the BRCA-2 protein was $-7.2 \mathrm{kcal} / \mathrm{mol}$ also include Ki values. MD simulation was performed using Desmond. Insertion results show that the amygdalin ligand binds more strongly to the BRCA-2 protein than to the BRCA-1 protein. MD simulation for the highly active inhibitor Amigydalin in complex with protein BRCA-2 revealed that the stabilization of ligand was achieved due to the formation of uninterrupted hydrophobic interactions. Due to the binding power of amygdalin ligand, it reveals a unique structure for breast cancer and it is thought to be a reference for designing new molecules with the same structure against cancer and applying these molecules in vivo and in vitro studies.

\section{Introduction}

Drug research and development is wide-ranging, expensive, time consuming, and fraught with risk. It is calculated that it takes 12 years for a drug idea to enter the market and the average money spent for it is more than $\$ 800$ million. For this reason, many new technologies have been developed and applied in drug research and development to shorten the research time and reduce its cost. Computer-aided drug design (CADD) is one such evolutionary technology [1] Since the discovery of the first insertion algorithm by Kuntz et al. in the 1980s, many different insertion approaches and tools have been developed [2]. Molecular docking can be defined as the structure prediction of receptor-ligand complexes. The receptor is usually a protein or protein oligomer, while the ligand is a small molecule or other protein. Virtual scanning with molecular insertion is increasingly important in drug discovery.

Autodock Vina [3] uses a combination of knowledge-based potentials and empirical scoring functions as the scoring function. The method derives empirical information from conformational experience of receptor-ligand complexes and experimental affinity calculations. Autodock Vina uses schoastic global improvement approaches, including algorithms such as genetic algorithms, particle-agglomeration optimization, and simulated annealing. Since it is compatible with Autodock4, using the tools of this program is seen as an advantage [3].

Amygdalin ( $D$-mandelonitrile- $\beta$-D-gentiobioside) is a cyanogenetic glycoside that is abundant in nature and is especially obtained from fruit seeds (macaroon, peach, apricot, etc.) [4]. Following oral ingestion of amygdalin, hydrogen cyanide ( $\mathrm{HCN})$, which is highly toxic along with other by-products, is released as a 
result of its breakdown in the digestive system [5]. There are several ways in which cyanide is metabolized in humans. Approximately $80 \%$ of cyanide taken into the body is converted to thiosionate ( $\mathrm{SCN}$-) by sulfurizing in the presence of thiosulfate by the activity of the rhodanase (thiosulfate sulfur transferase) enzyme in the liver, and thiosionate is also excreted in the urine [6, 7]. In addition, the 3mercaptopyruvate sulfur transferase enzyme provides the conversion of cyanide to thiosionate [8]. Although the concentration of enzymes that enable the conversion of cyanide to thiocyanate varies according to tissues, it has been reported that the highest amount is observed in the liver and kidneys [9]. Cyanide reacts with the amino acid cysteine to aminothiazolinecarboxylic acid and iminothiazolidinecarboxylic acid. In another mechanism, hydroxycobalamin converts cyanide into harmless cyano-cobalamine and then thiocyanate. These by-products are also excreted in the urine [6, 7]. It has been stated that there are no convincing data that amygdalin inhibits tumor development rapidly and significantly in patients with advanced disease, but whether amygdalin has a therapeutic effect needs clarification [10]. As can be understood from the literature information, it has not been clarified yet whether amygdalin has therapeutic properties. Discussions and research on the subject are ongoing. Although the issue has not been clarified, amygdalin tablets are still commercially available as natural dietary supplements under the names of "laetrile" or vitamin "B17" [11].

Breast cancer is the most common cancer and the cause of death in women $[12,13]$. In developed countries, it is predicted that one out of every 8 women will develop breast cancer during their lifetime, and the decrease in mortality draws attention despite the increase in its prevalence. Radiotherapy, longterm postmenopausal hormone replacement therapies, long-term oral contraceptive use, chronic alcohol use, postmenopausal obesity, benign proliferative breast diseases, presence of atypical hyperplasia as a result of previous biopsy, presence of lobular carcinoma in situ, dense breast structure in mammography, familial and genetic factors increase the risk of breast cancer. The most common genetic risk factors are BRCA 1 and BRCA 2 mutations.

In this study, which was carried out for the first time, it was aimed to examine the use of amygdalin in breast cancer treatment by coupling to the active regions of BRCA-1 and BRCA-2 genes by molecular docking method.

\section{Material And Method}

\section{Molecular Modeling Studies:}

\section{Ligand System}

Amygdalin was taken from PubChem (https://pubchem.ncbi.nlm.nih.gov) database in sdf format. Converted from Open Babel GUI program to pdb format.

\section{Protein system}


Crystal structures of BRCA-1 (PDB ID: 1T2V) and BRCA-2 (PDB ID: 1YJ) genes were obtained from Protein Data Bank (www.rcsb. Org). In the study, one of the genes, BRCA-1 a subunit, was conducted on BRCA-2 $\beta$ chains. All polar hydrogens have been added with the Discovery Studio 2020 [14] modeling package to reduce the tension of the crystal structure and make the proteins available for use in the Autodock simulation program. The structure obtained has been minimized in vacuum environment; during minimization, the heavy atoms are fixed at the initial crystal coordinates; the hydrogens are released to allow them to move. Autodocktools graphical user interface program was used to prepare proteins and ligands. Gasteiger charges were calculated and non-polar hydrogens joined with carbon atoms. For the macromolecules, the generated pdbqt files are saved.

\section{Molecular Docking}

Molecular docking is a computational procedure for estimating the binding mode and binding affinity of a ligand (drug molecule) with a protein (receptor) of known 3D structure. AutoDock Vina [3] version 1.1.2 was used to insert drug molecules into the drug binding sites of the BRCA-1(PDB ID:1T2V) and BRCA2 (PDB ID: 1IJY) protein. The introduction to the protocol includes the 3D structure of the protein receptor and ligands and a defined search conformational domain. The output gives a series of poses (receptorligand) ordered by the estimated binding energy $\Delta \mathrm{G}$ in $\mathrm{kcal} / \mathrm{mol}$. AutoDock Vina is set to generate a maximum of 20 poses via the num_modes command. Flexibility was allowed to the amygdalin molecules, while the protein receptor was kept solid throughout the insertion process. The search domain was defined to encompass two different BRCA-1 and BRCA-2 amygdalin binding sites[3]Discovery Studio 2020 programs, ligand-protein interactions of amygdalin in the active site were investigated [15].

\section{Molecular Dynamics Simulation}

The stability of the docked Amigydalin/1T2V and Amigydalin/1YJ complex was investigated by performing a $50 \mathrm{~ns} \mathrm{MD} \mathrm{[16]} \mathrm{simulation} \mathrm{study.} \mathrm{The} \mathrm{complex} \mathrm{in} \mathrm{the} \mathrm{explicit} \mathrm{solvent} \mathrm{system} \mathrm{with} \mathrm{OPLS3}$ force field was studied using Desmond module of Schreodinger 2019-4. The molecular system was solvated with crystallographic water (TIP3P) molecules [17] under orthorhombic periodic boundary conditions for $10 \AA$ buffer region. The overlapping water molecules are deleted, and the system was neutralized by adding $\mathrm{Na}^{+}$as counter ions. The total system consists of 66,817 atoms and 19,060 water molecules (PDB ID: 1IYJ). The total system consists of 101,833 atoms and 27,986 water molecules (PDB ID: 1T2V). An ensemble (NPT) of Nose-Hoover thermostat [18] and barostat was applied to maintain the constant temperature (300K) and pressure (1 bar) of the systems, respectively. A hybrid energy minimization algorithm with 1000 steps of steepest descent followed by conjugate gradient algorithms was utilized. Another algorithm, limited memory Broyden-FletcherGoldfarb-Shanno (LBFGS) algorithm with convergence threshold gradient of $1 \mathrm{kcal} / \mathrm{mol} / \AA ̊$ was also employed for energy minimization. A Smooth Particle Mesh Ewald method for calculating long range electrostatic interactions with a cut-off radius of $9 \AA$ for short range van der Waals and Coulomb interactions was used. Multiple time step RESPA integration (reference system propagator algorithms) was used in the dynamics study for bonded, near and far-bonded interactions with 2, 2 and $6 \mathrm{fs}$, respectively. The data were collected for every 100ps, and the obtained trajectory was analyzed with Maestro graphical interphase. 


\section{Results}

\section{Molecular Docking Results}

According to the results of the molecular modeling study: The BRCA-1 gene modeling results of the amygdalin ligand are shown in Table 1, the molecular modeling patterns are in Fig. 1, the protein-ligand interaction hydrophobic content is in Fig. 2, the bond structures of the amygdalin ligand to the PDB ID:1T2V protein are shown in Fig. 3 ( The amygdalin ligand of 1T2V and PHE1772, THR1773, THR1777 and ASP1778 form four hydrogen bonds, GLY1770 creates 1 amide- $\pi$ bond and-alkyl bond through PR01771), 1T2V pharmacophore study of amygdalin is shown in Fig. 4.

BRCA-2 gene modeling results of amygdalin ligand are shown in Table 2, molecular modeling patterns are shown in Fig. 5, protein-ligand interaction hydrophobic content is shown in Fig. 6, and the bond structures of amygdalin ligand to PDB ID:1IYJ protein are shown in Fig. 7 (1IYJ's amygdalin ligand with ALA2612 ALA2613, ALA2686, ASN2744 and HIS2938 form five hydrogen bonds, one amide-cation bond with LYS2959, $\pi$-alkyl bond with ARG2960 and carbon-hydrogen bond with GLY2746), 1IYJ pharmacophore study of amygdalin is shown in Fig. 8.

Table 1

In Silico Study Results of the Amygdalin Ligand at 1T2V

\begin{tabular}{|llllll|}
\hline $\begin{array}{l}\text { Results } \\
\text { Analysis } \\
\text { Software }\end{array}$ & $\begin{array}{l}\text { Visualization } \\
\text { Sofware }\end{array}$ & Protein & Ligand & $\begin{array}{l}\text { Docking } \\
\text { Score }\end{array}$ & Amino Acid Residue \\
\hline $\begin{array}{l}\text { Autodock } \\
\text { Vina }\end{array}$ & $\begin{array}{l}3 \text { D BIOVIA } \\
\text { Discovery }\end{array}$ & 1T2V & Amygdalin & $-4,8$ & $\begin{array}{l}\text { GLU1817, THR1816, TRP1815, } \\
\text { PRO1771, GLY1770, } \\
\end{array}$ \\
& $\begin{array}{l}\text { Studio } \\
\text { Visualizer }\end{array}$ & & & PHE1772,THR1777 \\
\end{tabular}

Table 2

In Silico Study Results of the Amygdalin Ligand at 1IJY

\begin{tabular}{|llllll|}
\hline $\begin{array}{l}\text { Results } \\
\text { Analysis } \\
\text { Software }\end{array}$ & $\begin{array}{l}\text { Visualization } \\
\text { Sofware }\end{array}$ & Protein & Ligand & $\begin{array}{l}\text { Docking } \\
\text { Score }\end{array}$ & Amino Acid Residue \\
\hline $\begin{array}{l}\text { Autodock } \\
\text { Vina }\end{array}$ & 3 D BIOVIA & 1IJY & Amygdalin & $-7,2$ & $\begin{array}{l}\text { ALA2612, ALA2613, ALA2686, } \\
\text { ASN2744, GLY2746, HIS2938, } \\
\text { Liscovery }\end{array}$ \\
& $\begin{array}{l}\text { Studio } \\
\text { Visualizer }\end{array}$ & & & \\
& & & & \\
\hline
\end{tabular}




\section{Molecular Dynamics Simulation Results of 1T2V}

A 50-ns molecular dynamic simulation was performed to understand the molecular insights involved in binding of Amigydalin in the active pocket of $1 \mathrm{~T} 2 \mathrm{~V}$. From the obtained trajectory analysis, the RMSD of protein $\mathrm{Ca}$, backbone and heavy atoms was observed in the range of $5.85-8.7 \AA$, respectively (Fig. 9). The $\mathrm{Ca}$ atoms fluctuated in the range of 5.85-8.7 $\AA$ and finally stabilized after $26 \mathrm{~ns}$ of simulation with a RMSD value of $8.5 \AA \AA$. Higher fluctuations (up to $8.7 \AA ̊$ ) in RMSD were observed at $26 \mathrm{~ns}$. Over the course of simulation, stable hydrophobic interactions were very low observed with Trp1815, lle6, Val1740, Ala1823. The flexibility of residues on ligand binding is analyzed using metrics of root mean square fluctuations (RMSFs) (Fig. 10).

A total of 43 ligand contacts (Fig. 11) were formed with amino acids of protein, from Tyr4, Asp1692, Gly1770, Glu1817. From Fig. 12, it was stated that the ligand is stabilized by forming majority of hydrophobic interactions ( $32 \%$ of simulation time) with residues Tyr4. The timeline representation of protein-ligand contacts is outlined in Fig. 12. The 2D-trajectory interaction diagram (Fig. 13) depicts that the hydrogen bond formed by the docking pose with Tyr4 is preserved in the MD trajectory pose. The RMSF (Fig. 14) of ligand with respect to initial frame was observed in the range of $0.5-1.6 \AA$. Other ligand properties (Fig. 14) such as radius of gyration, molecular surface area, solvent accessible surface area and polar surface area of ligands were observed in the range of $1.70-3.89 \AA, 380.0-436.0 \AA 2,200.00-$ $653.12 \AA 2$ and $300.00-385.00 \AA 22$, respectively.

\section{Molecular Dynamics Simulation Results of 1IJY}

A 50-ns molecular dynamic simulation was performed to understand the molecular insights involved in binding of Amigydalin in the active pocket of 1IJY. From the obtained trajectory analysis, the RMSD of protein $\mathrm{Ca}$, backbone and heavy atoms was observed in the range of 7.00-7.8Å, respectively (Fig. 15). The $\mathrm{Ca}$ atoms fluctuated in the range of 7.00-7.8 $\AA$ and finally stabilized after $40 \mathrm{~ns}$ of simulation with a RMSD value of 7.5Å. Higher fluctuations (up to $7.8 \AA$ ) in RMSD were observed at $30-35 \mathrm{~ns}$ and $40 \mathrm{~ns}$. Later the system is totally equilibridated and coverged. Over the course of simulation, stable hydrophobic interactions were low observed with Ala2686, Pro2730, Gly2743, His2938. The flexibility of residues on ligand binding is analyzed using metrics of root mean square fluctuations (RMSFs) (Fig. 16).

A total of 23 ligand contacts (1IJY) (Fig. 17) were formed with amino acids of protein, from Ser2709, Ser2712 to Asn2744, Asp2663 to Glu2687. From Fig. 18, it was stated that the ligand is stabilized by forming majority of hydrophobic interactions (5-90\% of simulation time) with residues Asp2663, Ala2686, Ser2709, Ser2712 and Asn2744. It also formed hydrogen bonds with Gln2684, Gln2685, Pro2730, Gly2742, Gly2743, Val2941 and Lys2943 over the course of $10-65 \%$ of simulation trajectory. The timeline representation of protein-ligand contacts is outlined in Fig. 18. Figure 18 The 2D-trajectory interaction diagram (Fig. 19) depicts that the hydrogen bond formed by the docking pose with Ser2709, Asn2744 is preserved in the MD trajectory pose. Amigydalin donated one hydrogen bond to Ser2709 with $57 \%$, the nitrogen of acridine ring accepted one hydrogen bond with Asp2663 through water molecule with $53 \%$ of total simulation time, respectively. The RMSF (Fig. 20) of ligand with respect to initial frame 
was observed in the range of $0.5-1.1 \AA$. Other ligand properties (Fig. 20) such as radius of gyration, molecular surface area, solvent accessible surface area and polar surface area of ligands were observed in the range of $4.50-5.08 \AA, 392.0-416.0 \AA 2,80.75-253.82 \AA 2$ and $302.74-364.72 \AA 2$, respectively.

\section{Discussion}

Breast cancer is most common in women in the world and in Turkey and that is the most common cause of cancer death. According to the 2018 data of IARC (International Agency for Research on Cancer) affiliated to the WHO (World Healt Organization), the number of newly diagnosed breast cancer patients worldwide is $2,000,088$, and the difference between lung cancer, the most common cancer, is only 5.000 is up [12]. The incidence of breast cancer in Turkey $50 / 100,000$ is above is calculated as the number of patients newly diagnosed 22,500 in 2018 [12, 19].

The incidence of breast cancer in Turkey, in a study published in 1994, 24 / 100,000 is designated as (Fidaner et al., 2001). In the past 25 years, the incidence of breast cancer has increased approximately 2.5 times $[12,19]$. The reasons for this increase are: 1 ) Change in lifestyle (obesity, inactivity, not giving birth, late birth > 35 years), short-term lactation, early menarche, late menopause, long-term contraceptive pill and menopause treatment, etc.), 2) The aging of the population. 3) Awareness (warnings from the media, information and referrals for screening mammography in breast and menopause polyclinics, increase in the knowledge and education level of women, etc.), increase in the number of irregular mammography and 4) increase in the population. This rapid increase in the frequency of breast cancer in our country, prevention, requires serious work for screening and early diagnosis. For these reasons, much research is needed on new drug designs and the applicability of these drugs. In this study, it was aimed to highlight the binding mechanisms of amygdalin to BRCA-1 and BRCA-2 genes used in the diagnosis of breast cancer, and to reveal its suitability for use in in vivo and in vitro studies on breast cancer.

Until now, the exact cause of breast cancer has not been determined, and various genetic and environmental factors are involved in its development. Genetic mutations in some genes such as BRCA1, BRCA2, TP53, CDH1, MRE11A, NBN, PALB2, PTEN, RAD50, RECQL, RINT1, CHEK2, 1 and Survivin increase the development of breast cancer. Any abnormality in these genes increases the detection of breast cancer by testing $[20,21]$.

According to the studies carried out, it has been argued that amygdalin taken by natural means will increase its effect according to the method of application. As an example, Jaswal et al. showed that the amount of hydrogen cyanide produced by natural ingestion of amygdalin is different depending on the intestinal microbes that hydrolyze amygdalin. In the study conducted by Moertel et al., it was not observed that intravenous infusion of amygdalin into the human body caused neither cyanidemia nor toxicity symptoms $[22,23]$.

Makarevic et al. examined the levels of cyclin A, cyclin B and cyclin D proteins controlling the cell cycle by applying amygdalin to cancer patients for 14 days. It has seen that the levels of these proteins that control cell turnover decrease. As a result, amygdalin plays a regulatory role in the cell cycle by controlling 
the suppression of proteins that regulate the cell cycle. With this study, it was determined that it has anticancer activity [24].

Hill et al. reported that amygdalin was ineffective in treatment against B16 melanoma and BW5147 AKR leukemia [25]. However, Fukuda et al. found that amygdalin has tumor growth inhibitory and protective effects against tumor formation [26]. Following oral administration of amygdalin, prunacin, glucose, mandelonitrile, benzaldehyde, and $\mathrm{HCN}$ are released as a result of extensive hydrolysis by emulsin enzyme (Suchard et al., 1998) or $\beta$-glycosidase enzyme [27], which is present in the gastrointestinal system and synthesized by the bacteria therein [28]. The target enzyme that cyanide acts on is cytochrome oxidase, which is the terminal oxidase of mitochondrial oxygenated respiratory chain, and as a result of its inhibition, histotoxic anoxia occurs in cells [29]. The mechanism that comes into play endogenously to remove cyanide from the body is the conversion of cyanide to thiocyanate, a relatively less toxic compound, via the mitochondrial enzyme rhodonase [30], and its excretion in urine [31]. The rhodonase enzyme may be functional in the presence of sulfur groups [32] and therefore thiosulfate, a sulfur source, is used in the treatment of cyanide poisoning. Another substance used as an antidote is sodium nitrite. It is aimed to form methemoglobin by binding nitrites to hemoglobin and to selectively bind to methemoglobin by separating cyanide from cytochrome oxidase [33].

Amygdalin has been found to induce programmed cell death (apoptosis) in human prostate cancer cells (DU145 and LNCap) [34]. Park et al. in the study conducted by [35], it has been reported that amygdalin has an anti-carcinogenic effect by damaging the DNA involved in the cycle of human colon cancer cells and therefore can be used as a cancer drug. In addition, Makarević et al. in the study conducted by [24], it was found that amygdalin showed a significant anti-tumor activity on prostate cancer cells, and therefore, it was stated that more studies are needed on its use for therapeutic purposes.

In his literature review, [36] concluded that amygdalin has a positive effect in the treatment of arteriosclerosis and diabetes, and in the prevention of cancer formation. On the other hand, it has been determined that amygdalin does not show an anticarcinogenic effect and some of its degradation products have such activity [37]. It was stated by [38] that amygdalin is effective on tumor cells, but there is not enough study on its mechanism of action. Amygdalin has been found to damage bull semen cells depending on the dose used [39]. There are no convincing data showing that amygdalin prevents rapid and distinct tumor development, especially in patients with advanced disease, however, it has been stated that the therapeutic effect of amygdalin needs to be clarified [40].

As can be understood from the literature information, it has not been clarified yet whether amygdalin has therapeutic properties. Discussions and research on the subject are ongoing. Although the issue has not been clarified, amygdalin tablets are still commercially available as natural dietary supplements under the names "laetrile" or vitamin "B17" [11]. Today, many websites sell amygdalin and many doctors use amygdalin for treatment [40].

\section{Conclusion}


Molecular modeling installation studies were conducted to reveal the mechanism and effect of amygdalin binding to BRCA-1 and BRCA-2 protein. The free energy of amygdalin to bind to the BRCA-1 protein structure was $-4.8 \mathrm{kcal} / \mathrm{mol}$ and the free energy to bind to the BRCA-2 protein structure was $7.2 \mathrm{kcal} / \mathrm{mol}$. These results show that amygdalin ligand binds more strongly to BRCA-2 protein than BRCA-1 protein. MD simulation for the highly active inhibitor Amigydalin in complex with protein 1IJY revealed that the stabilization of ligand was achieved due to the formation of uninterrupted hydrophobic interactions. Due to the binding power of amygdalin ligand, it reveals a unique structure for breast cancer and it is thought to be a reference for designing new molecules with the same structure against cancer and applying these molecules in vivo and in vitro studies.

\section{Abbreviations}

BRCA-1:Breast cancer type 1

BRCA-2:Breast cancer type 2

CADD: Computer-aided drug design

CDH1: Cadherin-1 protein

CHECK 2: Checkpoint kinase 2

HCN: Hydrogen cyanide

IARC: International agency for research on cancer

MRE11A: Double-strand break repair protein MRE11

NBN: Nibrin

PALB2: Partner and localizer of BRCA2

PTEN: Phosphatase and tensin homolog

RAD 50: DNA repair protein

RECQL: ATP-dependent DNA helicase Q1

RINT1: RAD50-interacting protein 1

RMSD: Root mean square deviation

SCN: Thiosionate

TP53: Tumor Protein p53 
WHO: World Health Organization

\section{Declarations}

\section{ETHICAL APPROVAL}

Ethical approval is not required.

\section{CONSENT TO PARTICIPATE}

Yes

CONSENT TO PUBLISH

Yes

\section{AUTHORS CONTRIBUTIONS}

$E O, A G$. ID, MG, SY, EY and EBK designed and executed the business. AG, MD conducted the simulation study.

\section{FUNDING}

This work did not receive any fundings from external or internal agencies.

\section{COMPETING INTERESTS}

Authors declare no competing interests

\section{AVAILABILITY OF DATA AND MATERIALS}

All the data are available in the manuscript.

\section{References}

1. Tang Y, Zhu W, Chen K, Jiang H (2006) New Technologies in Computer-Aided Drug Design: Toward Target Identification and New Chemical Entity Discovery, Drug Discovery Today: Technologies, Medicinal Chemistry, Vol. 3, No. 3

2. Kuntz ID, Blaney JM, Oatley SJ, Lange R, Ferrin TE (1982) A geometric approach to macromoleculeligand interactions. J Mol Biol 161:269-288

3. Trott O, Olson AJ (2010) AutoDock Vina: improving the speed and accuracy of docking with a new scoring function, efficient optimization and multithreading. J Comput Chem 31:455-461

4. Haisman DR, Knight DJ (1967) The enzymic hydrolysis of amygdalin. Biochem J 103:528-534 
5. Soffer A (1976) Chihuahuas and Laetrile, chelation therapy, and honay from boulder, colo. Arch Intern Med 136:865-866

6. World Health Organization (2004) "Hydrogen Cyanide and Cyanides: Human Health Aspects". Concise International Chemical Assessment Document 61, World Health Organization, Geneva, Switzerland

7. Cabuk A, Kolankaya N (2012) Siyanürün Toksisitesi Ve Biyolojik Yıkımı, Mühendislik ve Fen Bilimleri Dergisi-Sigma, 30, 20-38, 2012

8. Zagrobelny M, Bak S, Rasmussen AN, Jørgensen B, Naumann CM, Møller BL (2004). “Cyanogenic Glycosides and Plant-Insect Interactions", Phytochemistry, 65, 293-306

9. Sylvester M, Sander C (1990) Immunohistochemical Localization of Rhodanese. Histochem J 22:197-200

10. Blaheta RA, Nelson K, Haferkamp A, Juengel E (2016) Amygdalin, Quackery or Cure? Phytomedicine 23(4):367-376

11. Wahab MF, Brettbach ZS, Armstrong DW, Strattan R, Berthod A (2015) Problems and Pitfalls in the Analysis of Amygdalin and its Epimer. J Agric Food Chem 63(40):8966-8973

12. Bray F, Ferlay J, Soerjomataram I, Siegel R, Torre LA, Jemal A (2018) Global Cancer Statistics: GLOBOCAN Estimates of Incidence and Mortality Worldwide for 36 Cancers in 185 Countries CA. Cancer J Clin 68(6):394-424. DOI:10.3322/caac.21492 Nov 2018 PMID: 30207593

13. Dogan N, Tograk D (2014) Female Breast Cancer Mortality Rates in Turkey. Asian Pacific Journal of Cancer Prevention, 15, 7569-73 PMID: 25292030 DOI: 10.7314/apjcp.2014.15.18. 7569

14. Bıovia DS (2016) Dassault Systèmes BIOVIA, Discovery Studio, 2019, San Diego: Dassault Systèmes

15. Laskowski A, Mark B (2011) LigPlot+: multiple ligand-protein interaction diagrams for drug discovery. J Chem Inf Model, Oct, 24, 51(10), 2778-86

16. Guo Z, Mohanty U, Noehre J, Sawyer TK, Sherman W, Krilov G (2010) Probing the alpha-helical structural stability of stapled p53 peptides: Molecular dynamics simulations and analysis. Chem Biol Drug Des 75(4):348-359. https://doi.org/10.1111/j.17470285.2010.00951

17. Jorgensen WL, Chandrasekhar J, Madura JD, Impey RW, Klein ML (1983) Comparison of simple potential functions for simulating liquid water. J Chem Phys, 79(2), 926-935. https:// doi.org/10.1063/1.445869

18. Martyna GJ, Klein ML, Tuckerman M (1992) Nose- Hoover chainsthe canonical ensemble via continuous dynamics. J Chem Phys 97(4):2635-2643. https://doi.org/10.1063/1.463940

19. Ozmen V (2008) Breast Cancer in the world and in Turkey. Meme Sağlığı Dergisi 4:7-12

20. Doosti A, Ghasemi DP, Davoudi N (2011) A p53 codon 72 polymorphism associated with breast cancer in Iranian patients. African Journal of Pharmacy Pharmacology 5(10):1278-1281

21. Ollier M, Radosevic-Robin N, Kwiatkowski F, Ponelle F, Viala S, Privat M, Uhrhammer N, BernardGallon D, Penault-Llorca F, Yves-Jean B, Bidet Y (2015) DNA repair genes implicated in triple negative familial non-BRCA1/2 breast cancer predisposition. Am J Cancer Res 5(7):2113-2126 
22. Jaswal V, Palanivelu J, Ramalingam C (2018) Effects of the Gut microbiota on Amygdalin and its use as an anti-cancer therapy: Substantial review on the key components involved in altering dose efficacy and toxicity. Biochem Biophys Rep, Jul, 14, 125-132

23. Moertel CG, Dockerty MB, Baggenstoss AH (1961) Multiple primary malignant neoplasm: II. Tumors of different tissues or organs. Cancer 14:231-237

24. Makarević J, Tsaur I, Juengel E, Borgmann H, Nelson K, Thomas C, Bartsch G, Haferkamp A, Blaheta $\mathrm{R}$ (2016) Amygdalin delays cell cycle progression and blocks growth of prostate cancer cells in vitro. Life Sci Feb 15:147. doi:10.1016/j.Ifs.2016.01.039. 137 - 42.

25. Hill GJ, Shine TE, Hill HZ, Miller C (1976) Failure of amygdalin to arrest B16 melanoma and BW5147 AKR leukemia. Canc Res 36:2102-2107

26. Fukuda T, Ito H, Mukainaka T, Tokuda H, Nishino H, Yoshida T (2003) Anti-tumor promoting effect of glycosides from prunus persica seeds. Biol Pharm Bull 26:271-273

27. Dorr RT, Paxinos J (1978) The current status of laetrile. Ann Intern Med 89:389-397

28. Haisman DR, Knight DJ (1967) The enzymic hydrolysis of amygdalin. Biochem J 103:528-534

29. Ivankovich AD, Braverman B, Kanuru RP, Heyman HJ, Paulissian R (1980) Cyanide antidotes and methods of their administration in dogs. Anesthesiology 52:210-216

30. Basu TK (1983) High-dose ascorbic acid decreases detoxification of cyanide derived from amygdalin (laetrile): studies in guinea pigs. Can J Physiol Pharmacol 61:1426-1430

31. Salkowski A, Penney DG (1994) Cyanide poisoning in animals and humans: a review. Vet Hum Toxicol 35:455-456

32. Adewusi SR, Oke OL (1985) On the metabolism of amygdalin. 2. the distribution of beta-glucosidase activity and orally administered amygdalin in rats. Can J Physiol Pharmacol 63:1084-1087

33. Baskin SI, Horowitz AM, Nealley EW (1992) The antidotal action of sodium nitrite and sodium thiosulfate against cyanide poisoning. J Clin Pharmacol 32:368-375

34. Chang HK, Shın MS, Yang HY, Lee JW, Kim YS, Lee MH, Kim J, Kim KH, Kim CJ (2006) Amygdalin Induces Apoptosis through Regulation of Bax and Bcl-2 Expressions in Human DU145 and LNCaP Prostate Cancer Cells. Biol Pharm Bull 29(8):1597-1602

35. Park HJ, Yoon SH, Han LS, Zheng LT, Jung KH, Uhm YK, Lee JH, Jeong JS, Joo WS, Yım SV, Chung JH, Hong SP (2005) Amygdalin Inhibits Genes Related to Cell Cycle in SNU-C4 Human Colon Cancer Cells. World J Gastroenterol 11(33):5156-5161

36. Aghadavod E (2016) Amygdalin; Is It an Anticancer and Antitumor Agent? Immunopathologia Persa 2(2):22

37. Chen Y, Ma J, Wang F, Hu J, Cui A, Wei C, Yang Q, LI F (2013) Amygdalin Induces Apoptosis in Human Cervical Cancer Cell Line HeLa Cells. Immunopharmacol Immunotoxicol 35(1):43-51

38. Song Z, Xu X (2014) Advanced Research on Anti-tumor Effects of Amygdalin. J Cancer Res Ther 10:3-7 
39. Tanyıldızı S, Bozkurt T (2004) In vitro Effects of Linamarin, Amygdalin and Gossypol Acetic Acid on Hyaluronidase Activity, Sperm Motility and Morphological Abnormality in Bull Sperm. Turkish J Vet Anim Sci 28(5):819-824

40. Blaheta RA, Nelson K, Haferkamp A, Juengel E (2016) Amygdalin, Quackery or Cure? Phytomedicine 23(4):367-376

\section{Figures}
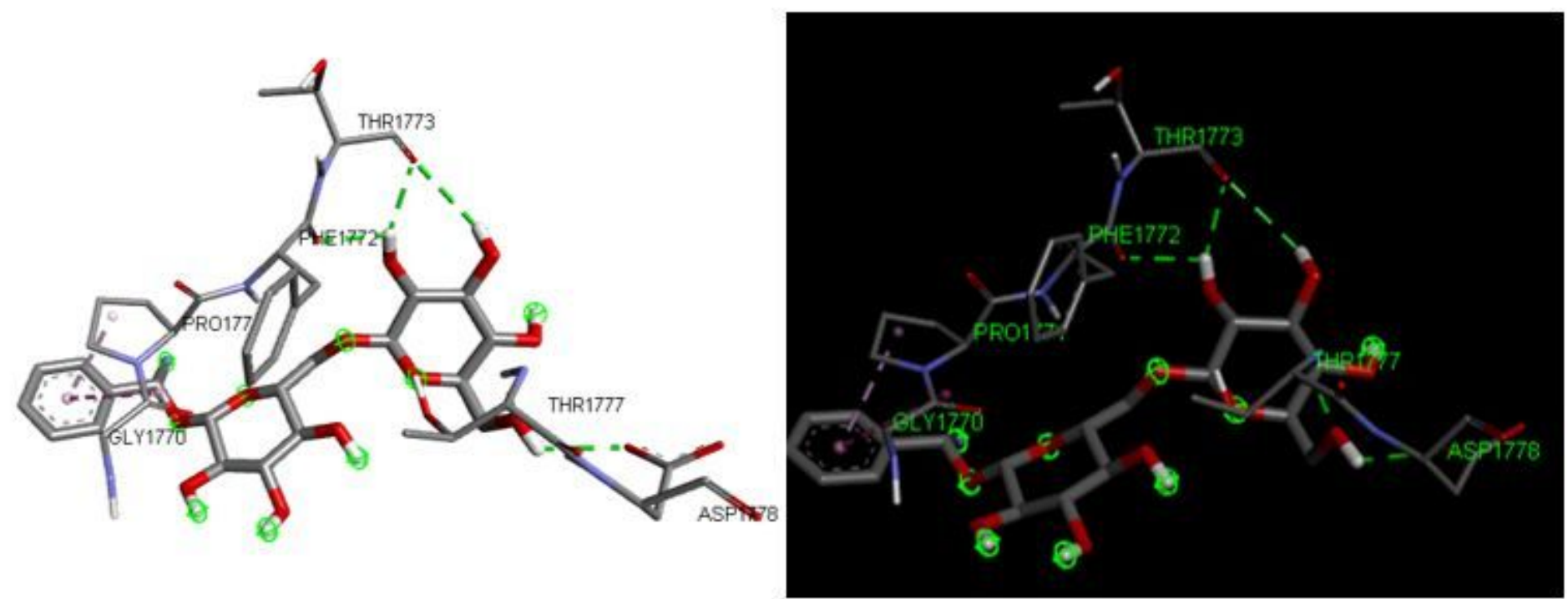

\section{Figure 1}

In Silico Study of the Amygdalin Ligand at 1T2V
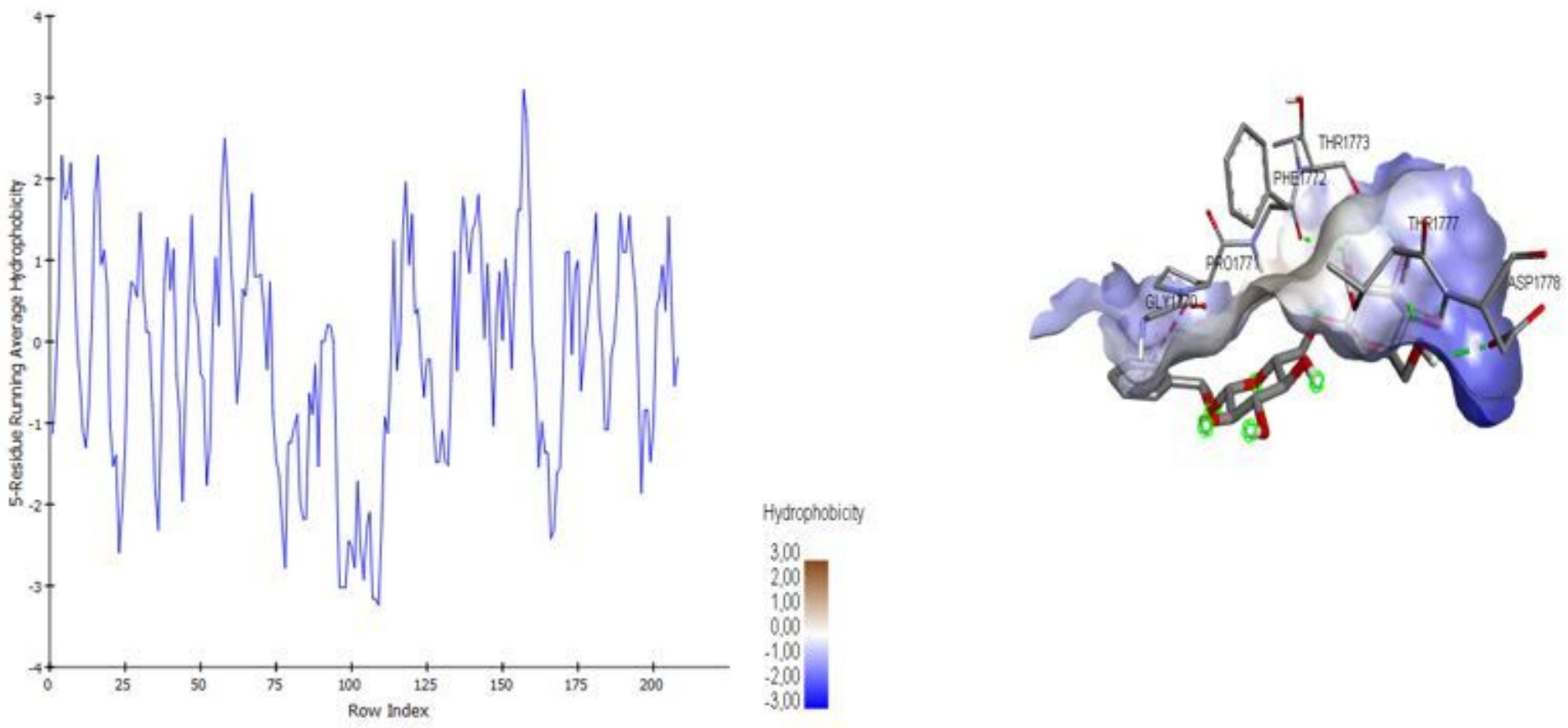
Figure 2

Hydrophobic content of protein-ligand (1T2V-Amygdalin) interaction

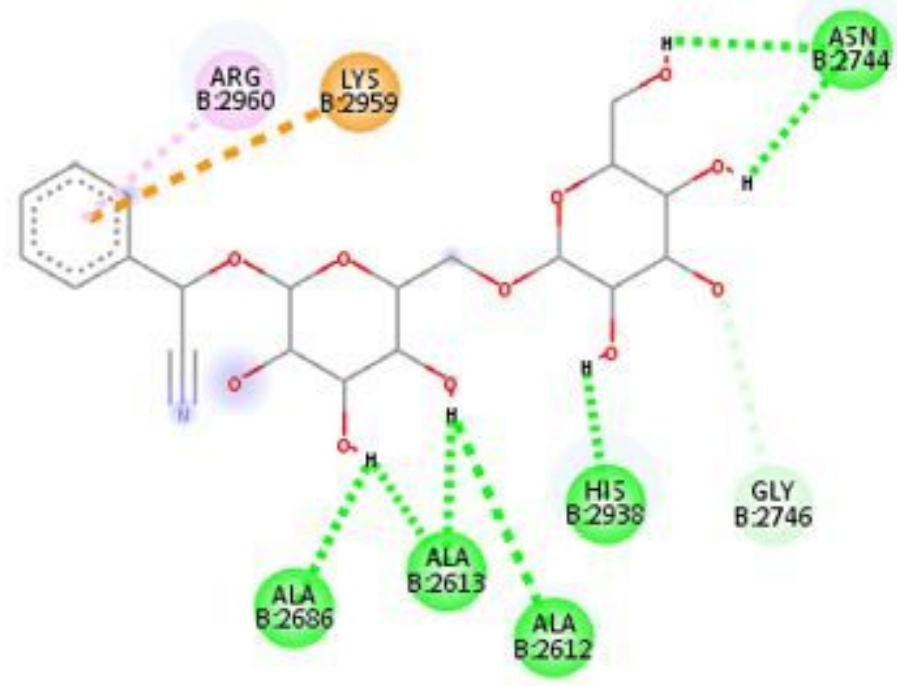

Interactions

Conventional Hydrogen Bond

Carbon Hydrogen Bond

Pi-Cation

Pi-Alkyl

\section{Figure 3}

Bond Structures in the 1T2V Protein of the Amygdalin Ligand

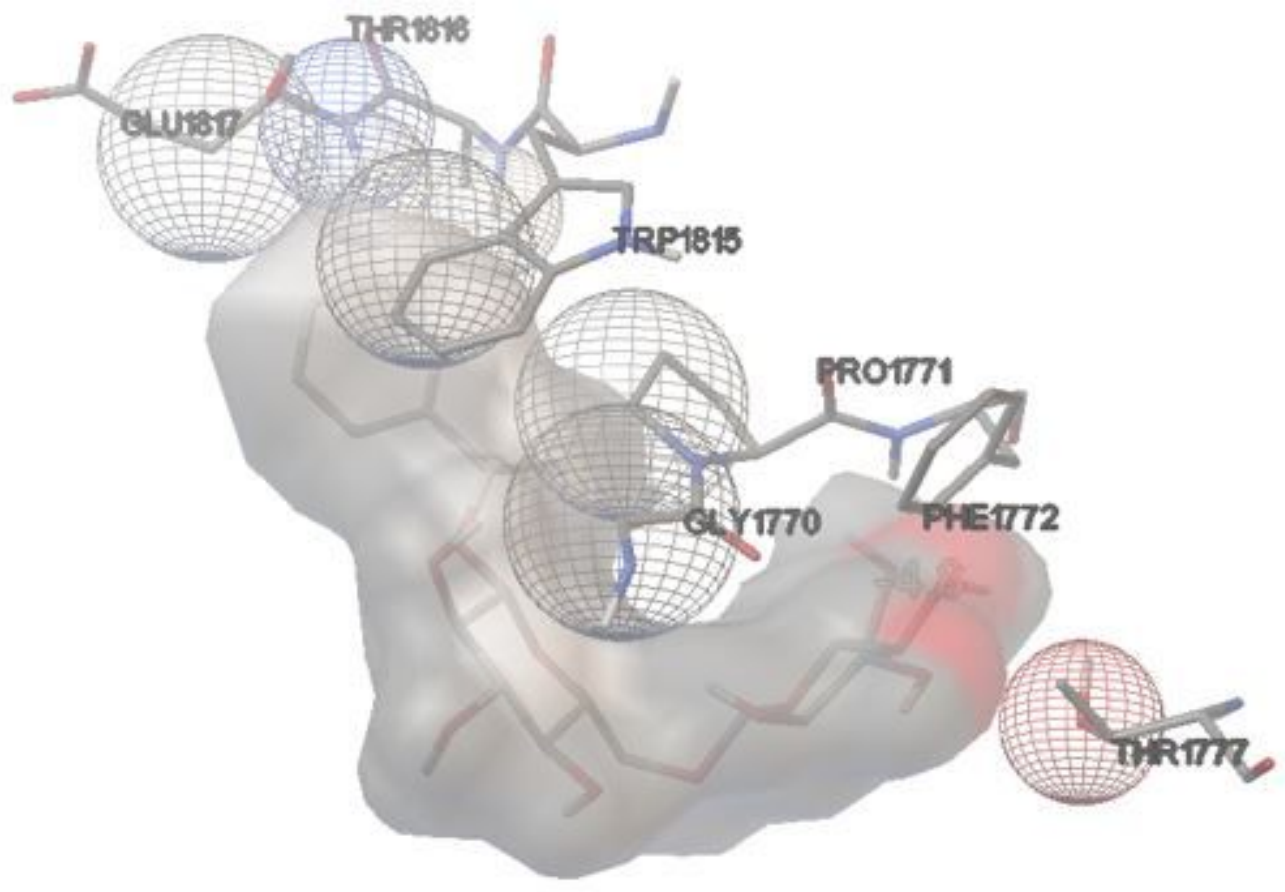


Figure 4

1T2V Pharmacophore Modeling Study of Amygdalin Ligand
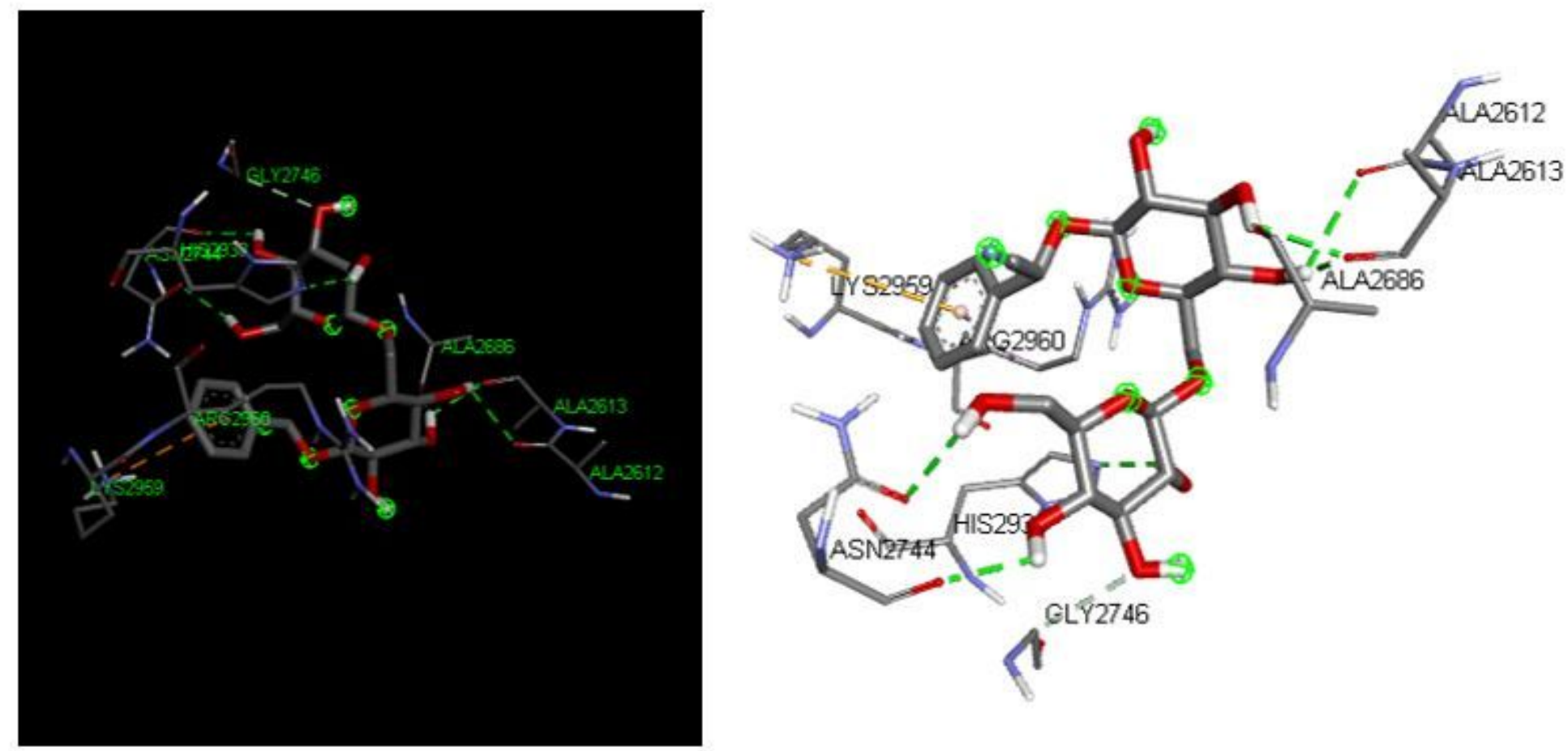

Figure 5

In Silico Study of the Amygdalin Ligand at 1IJY

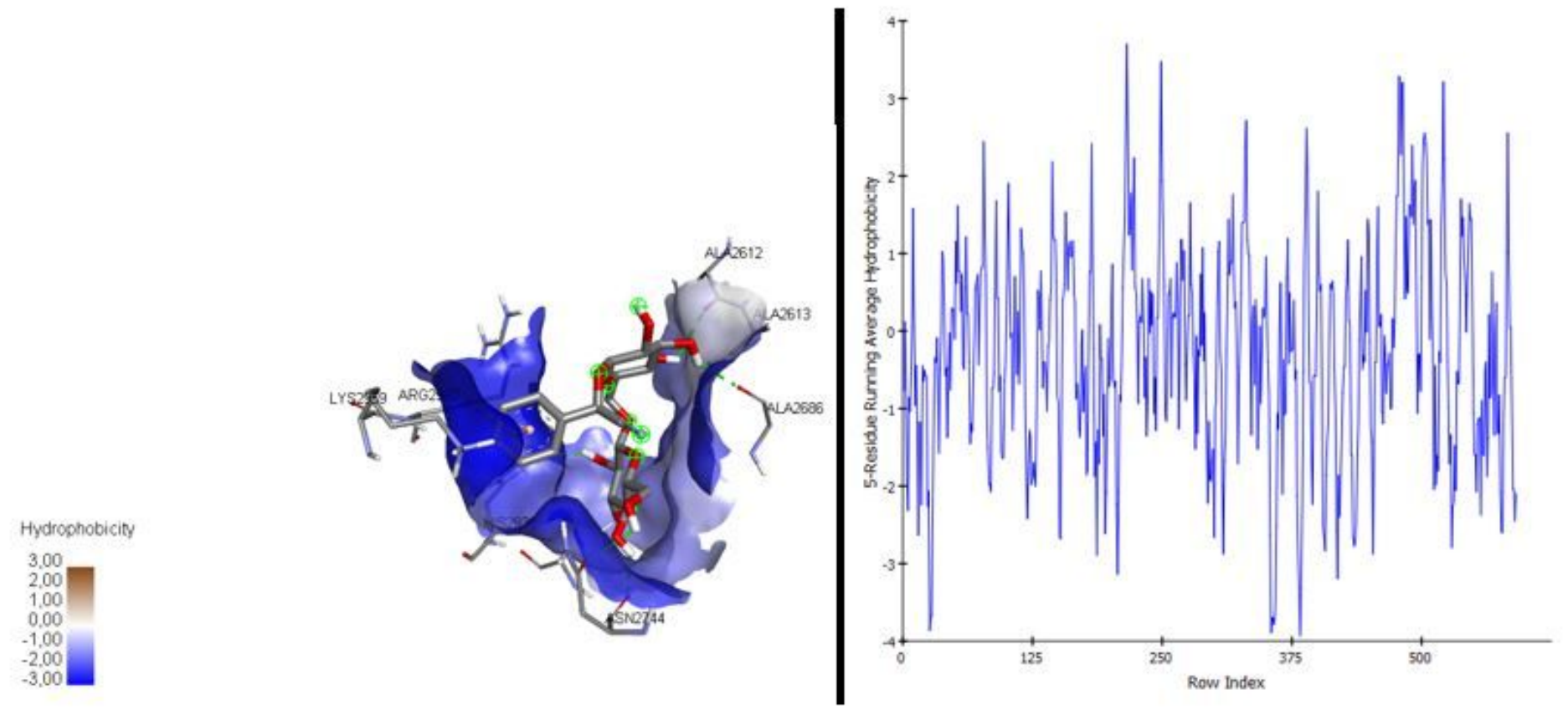

Figure 6

Hydrophobic content of protein-ligand (1IJY-Amygdalin) interaction 


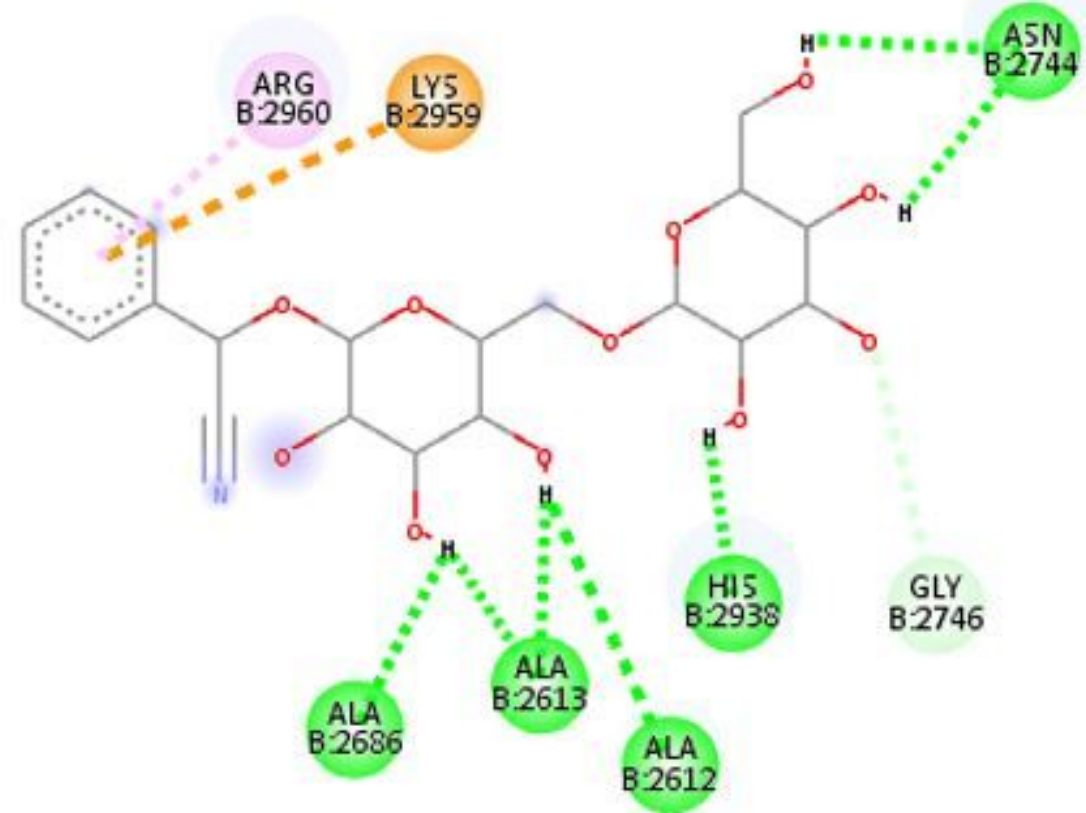

\section{Interactions}
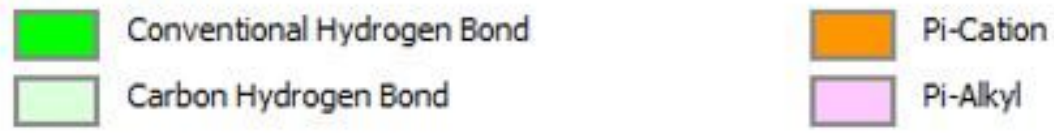

Figure 7

Bond Structures in the 1IJY Protein of the Amygdalin Ligand 


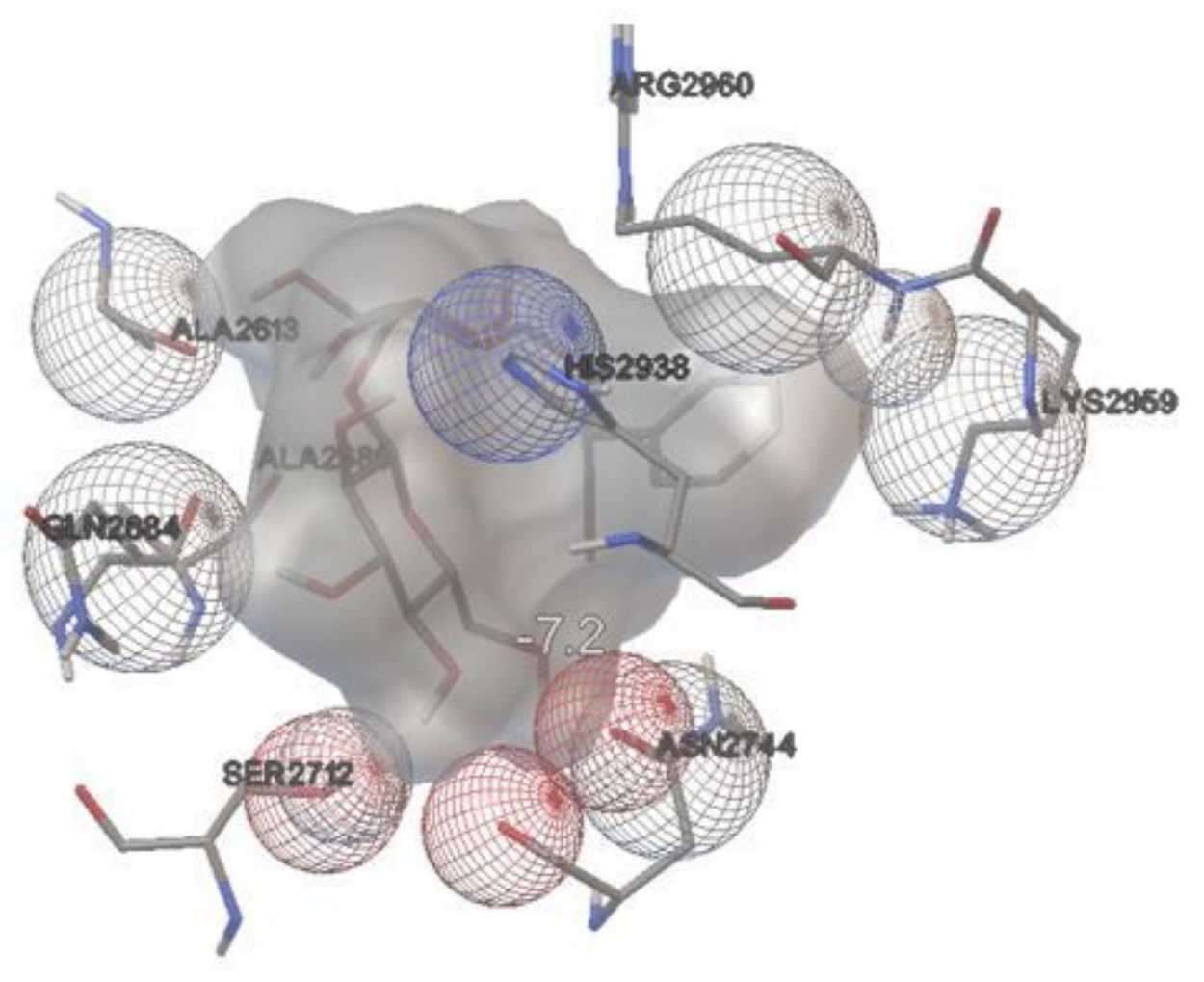

Figure 8

1IJY Pharmacophore Modeling Study of Amygdalin Ligand

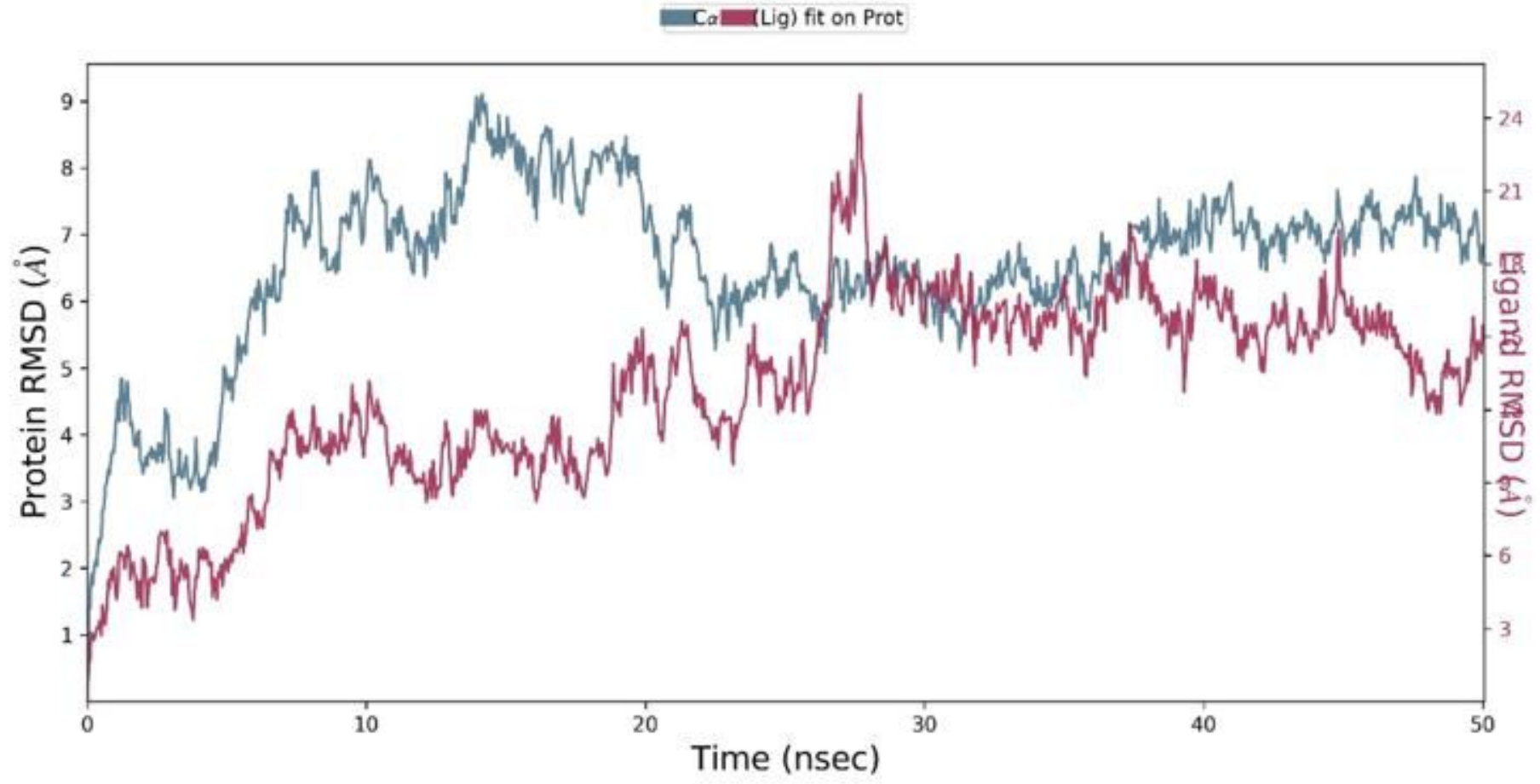

Figure 9 
RMSD $(\AA)$ of simulated protein 1T2V.pdb in complex with inhibitor Amigydalin during 50ns MD simulation.

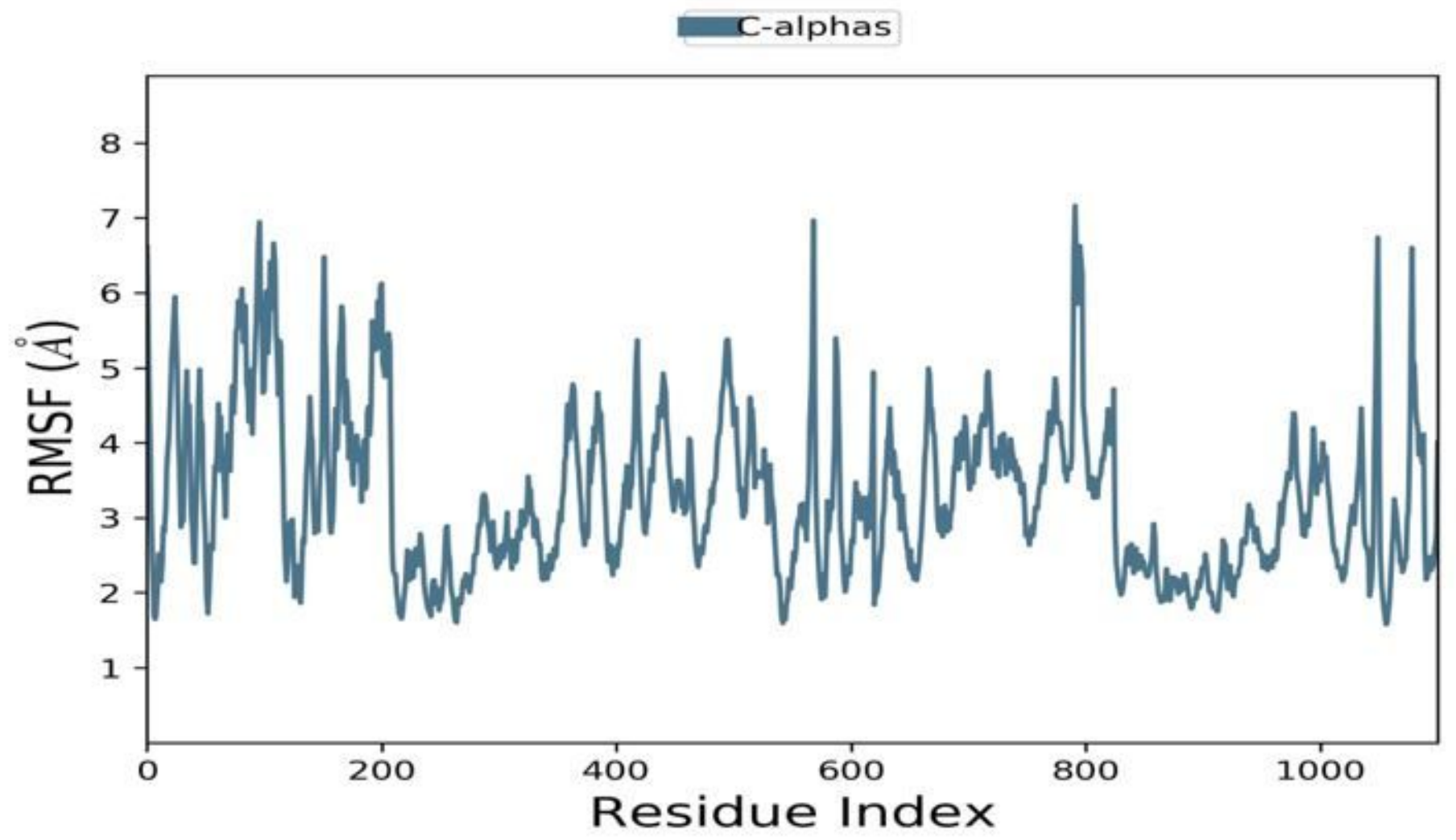

Figure 10

RMSF of simulated protein 1T2V.pdb in complex with inhibitor Amigydalin during 50ns MD simulation 

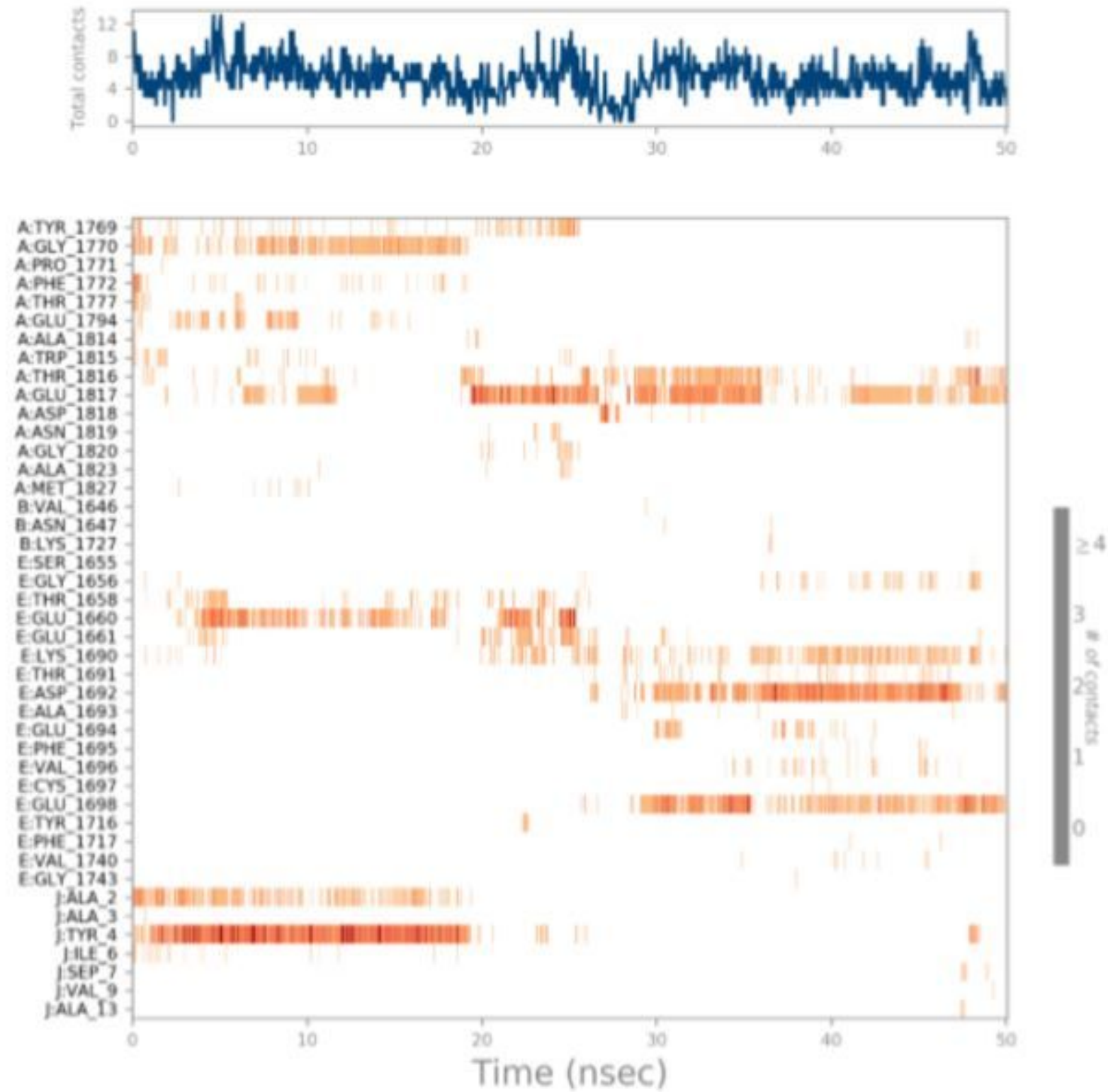

Figure 12

Time line representation showing different contacts formed by Amigydalin in complex with 1T2V.pdb during 50ns MD simulation. 


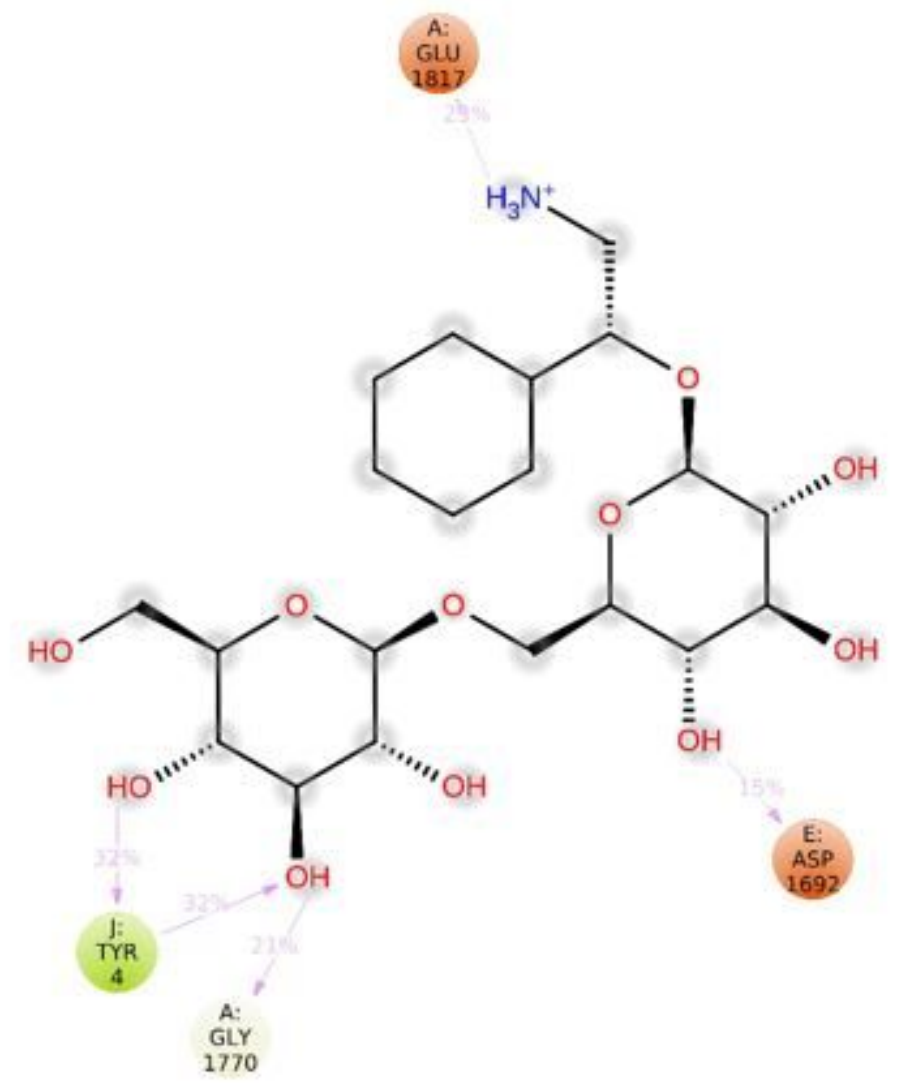

Figure 13

2D interaction diagram of Amigydalin in complex with 1T2V.pdb during 50ns MD simulation. 

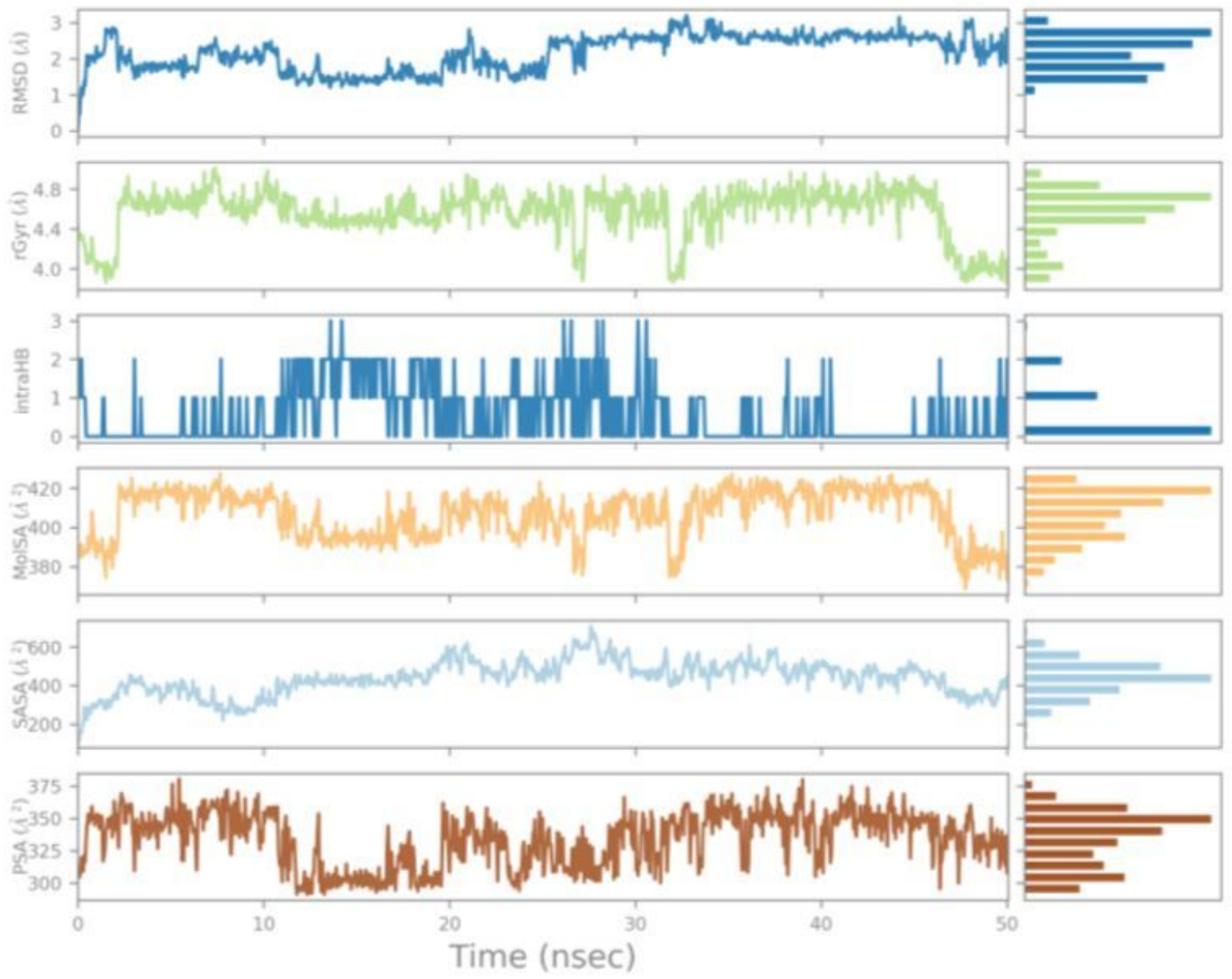

\section{Figure 14}

Ligand properties of Amigydalin in complex with 1T2V.pdb during 50ns MD simulation. 


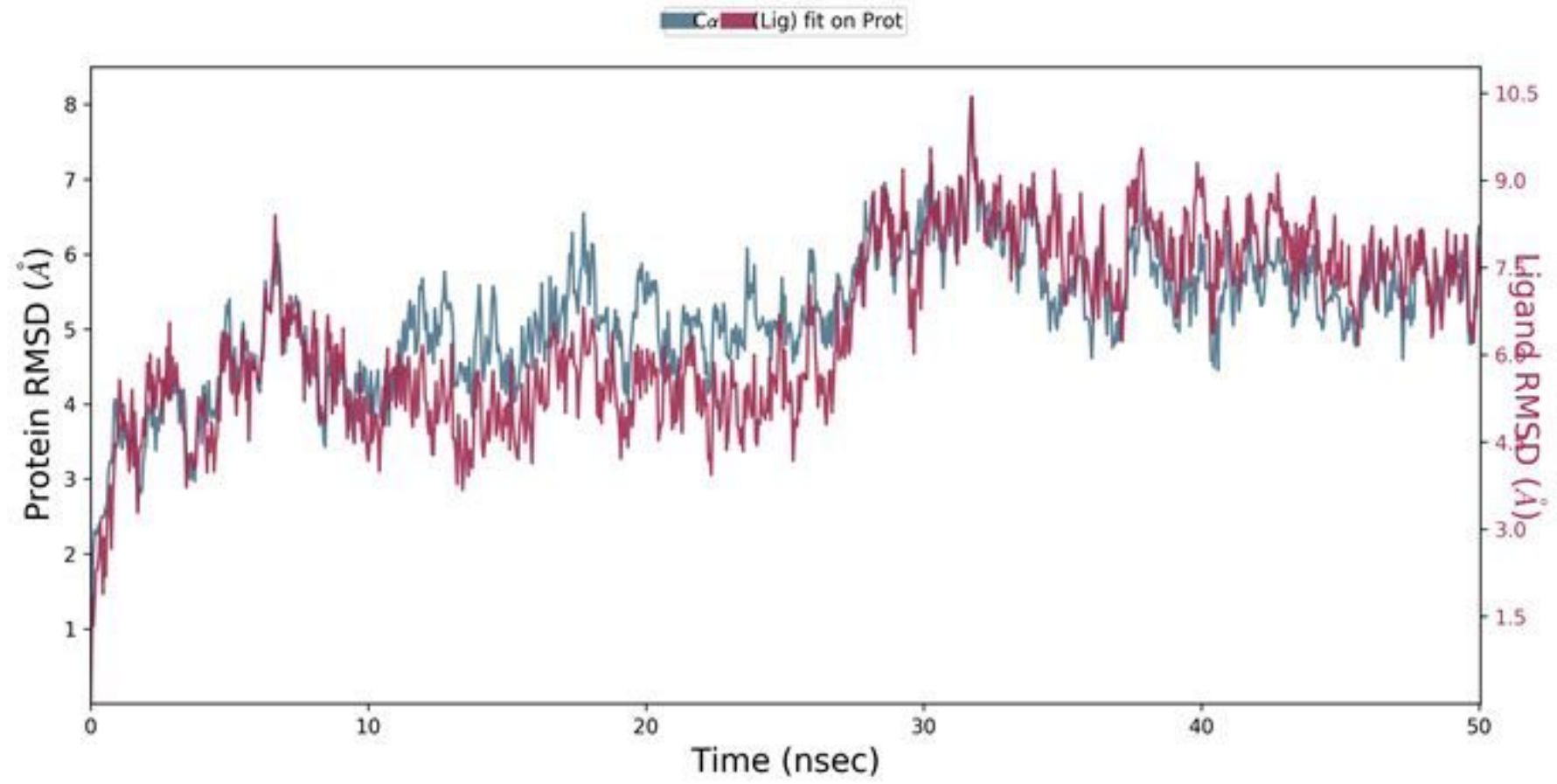

Figure 15

RMSD (Å) of simulated protein 1IJY.pdb in complex with inhibitor Amigydalin during 50ns MD simulation. 


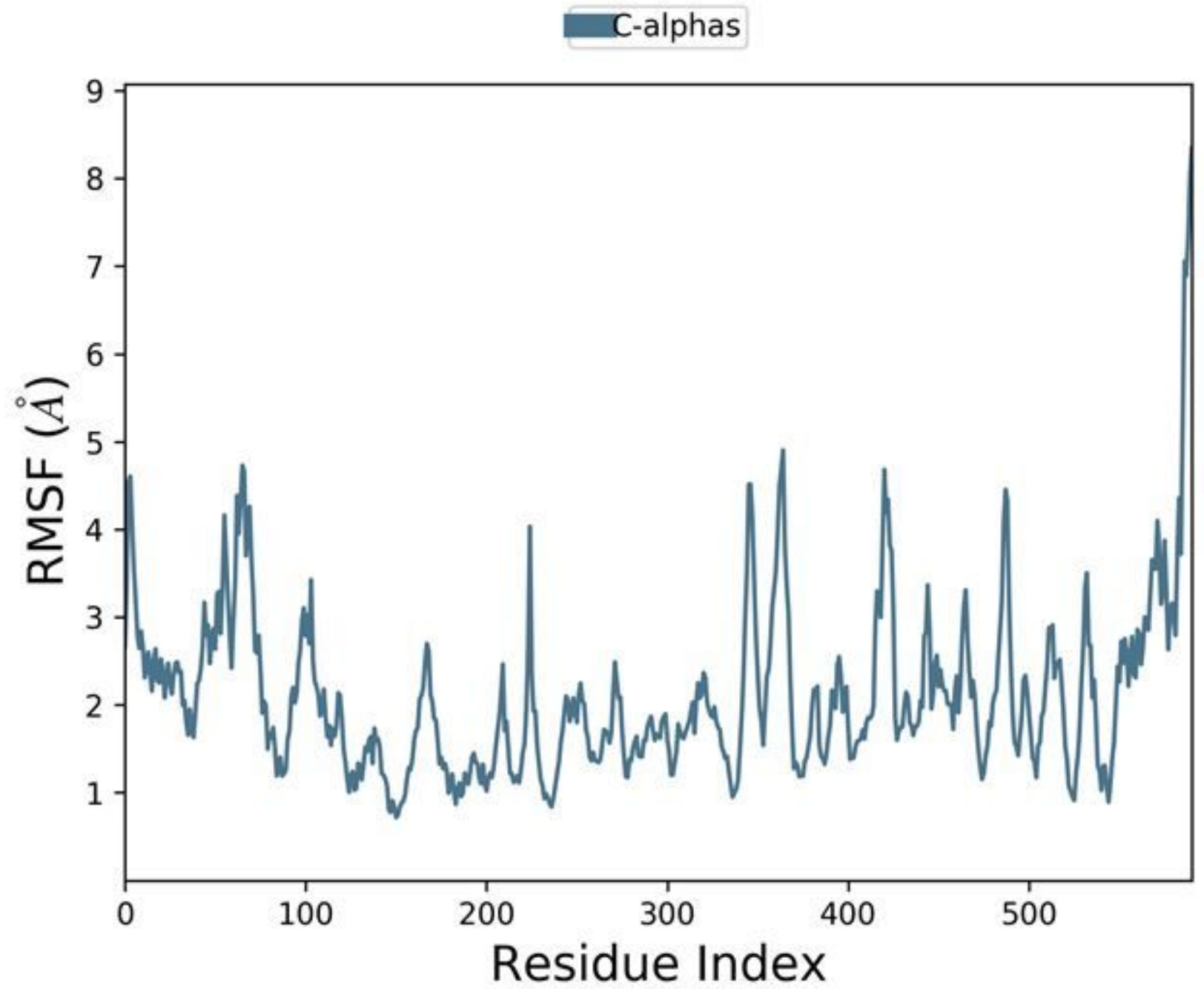

Figure 16

RMSF of simulated protein 1IJY.pdb in complex with inhibitor Amigydalin during 50ns MD simulation 


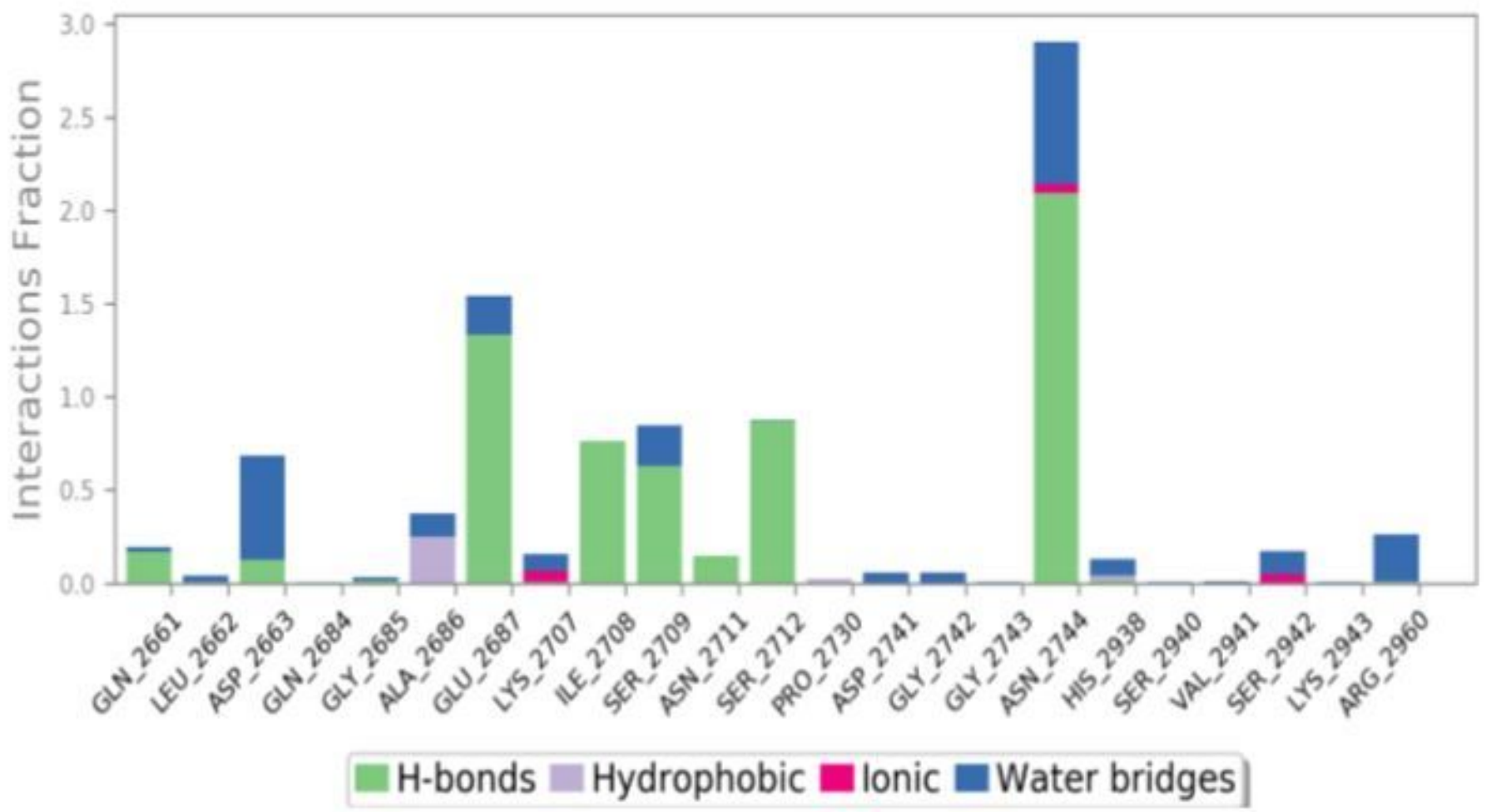

Figure 17

Interaction fraction of 1IJY.pdb complexed with Amigydalin during 50ns MD simulation. 

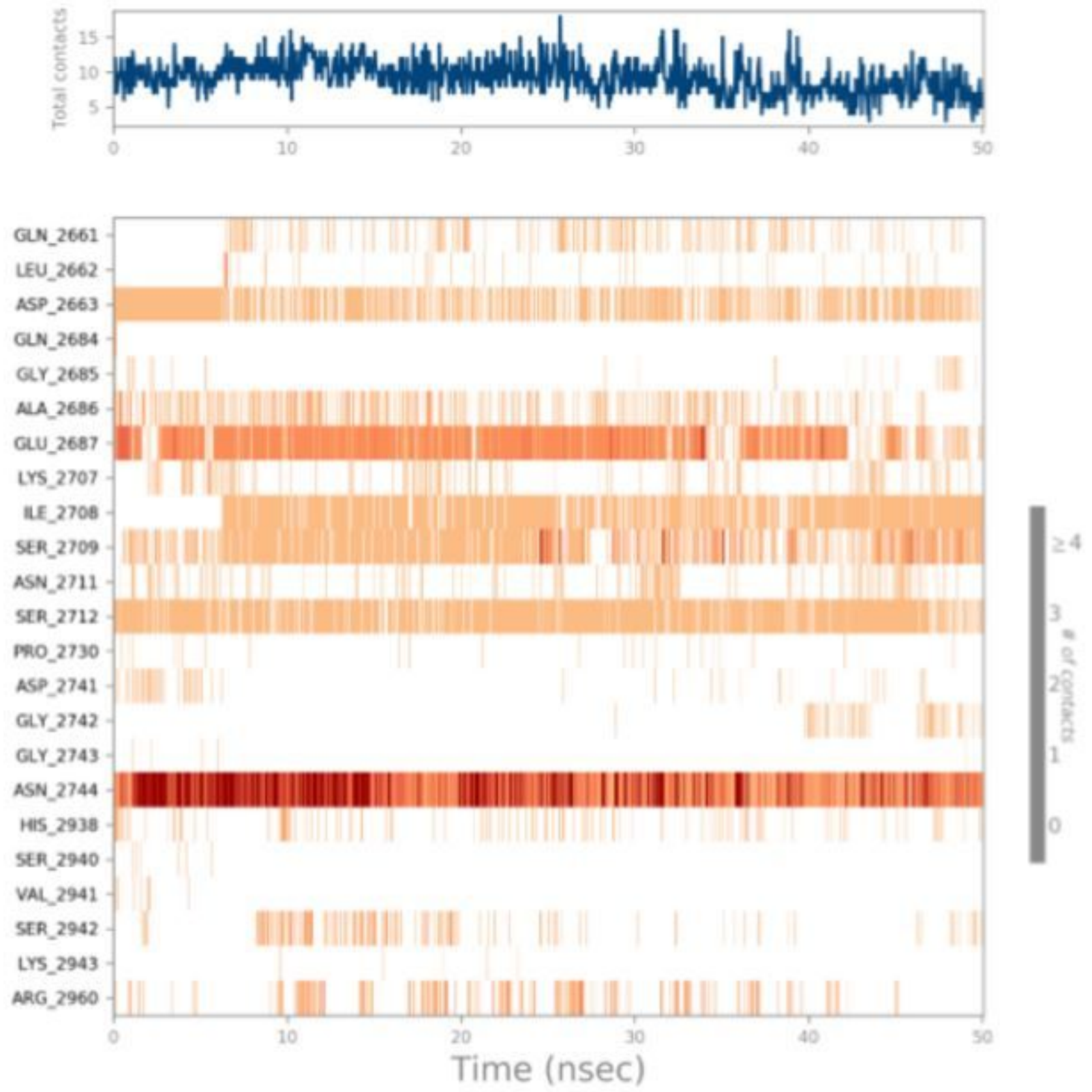

Figure 18

Time line representation showing different contacts formed by Amigydalin in complex with 1IJY.pdb during 50ns MD simulation. 


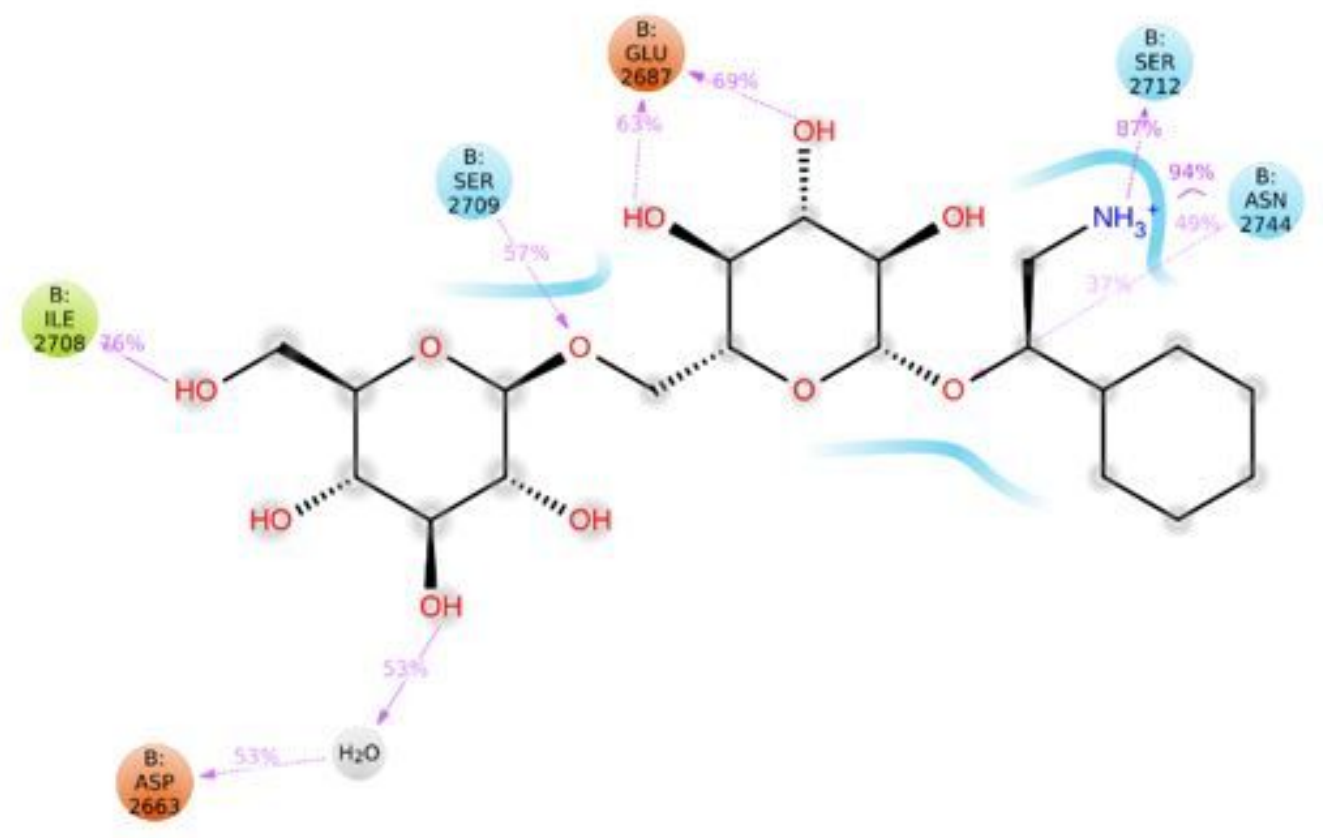

Figure 19

2D interaction diagram of Amigydalin in complex with 1IJY.pdb during 50ns MD simulation. 

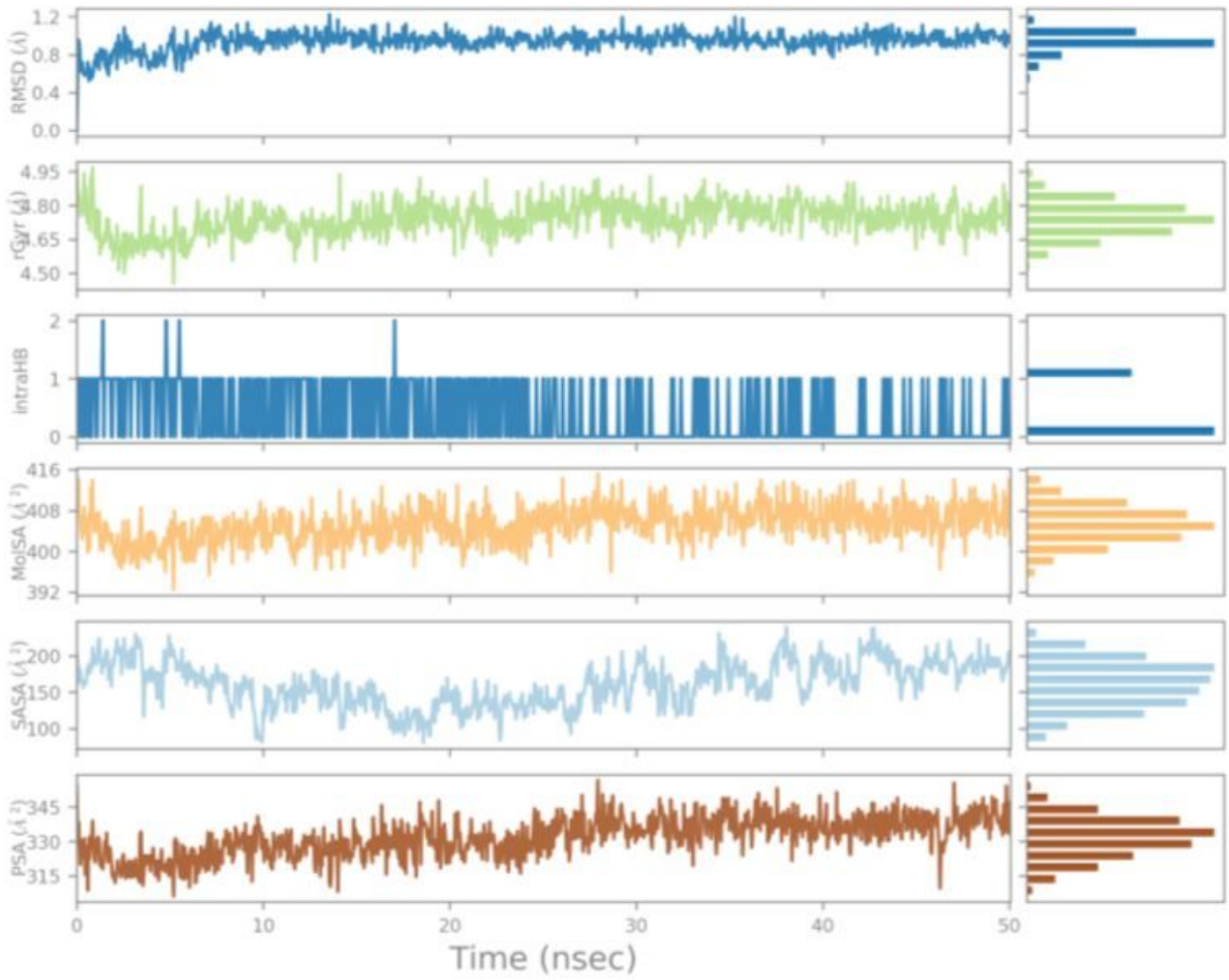

\section{Figure 20}

Ligand properties of Amigydalin in complex with 1IJY.pdb during 50ns MD simulation. 